\title{
Correction to: Diagnostic performance of fusion (US/MRI guided) prostate biopsy: propensity score matched comparison of elastic versus rigid fusion system
}

\author{
Mariaconsiglia Ferriero ${ }^{1}(1) \cdot$ Gabriele Tuderti - Gian Luca Muto ${ }^{1} \cdot$ Cristian Fiori $^{2}$. Alfredo Maria Bove ${ }^{1}$. \\ Riccardo Mastroianni ${ }^{1}$. Umberto Anceschi ${ }^{1}$ - Leonardo Misuraca ${ }^{1}$. Aldo Brassetti ${ }^{1}$. Sabrina De Cillis ${ }^{2}$. \\ Enrico Checcucci ${ }^{2} \cdot$ Salvatore Guaglianone ${ }^{1} \cdot$ Michele Gallucci $^{1} \cdot$ Francesco Porpiglia $^{2} \cdot$ Giuseppe Simone $^{1}$
}

Published online: 10 February 2022

(c) The Author(s), under exclusive licence to Springer-Verlag GmbH Germany, part of Springer Nature 2022

\section{Correction to: World Journal of Urology}

https://doi.org/10.1007/s00345-021-03921-0

Correction text:

The authors realized that there is a typographic mistake in Table 2 after the original publication of the article. The correct Table 2 is given below:

The original article can be found online at https://doi.org/10.1007/ s00345-021-03921-0.

Mariaconsiglia Ferriero

marilia.ferriero@gmail.com

1 Department of Urology, "Regina Elena" National Cancer Institute, Via Elio Chianesi 53, 00144 Rome, RM, Italy

2 San Luigi Gonzaga Hospital, University of Turin, Urology, Orbassano, Italy 
Table 2 Positive predictive value of PCa detection of elastic versus rigid fusion system, stratified for PI-RADS Score in a per target analysis

\begin{tabular}{lllll}
\hline Per target PPV $(\%)$ & PI-RADS score & Elastic System $N(\%)$ & Rigid System $N(\%)$ & $p$ \\
\hline Any GS & Any & $58 / 83(69.8)$ & $47 / 83(56.6)$ & 0.077 \\
& 3 & $5 / 18(27.8)$ & $7 / 19(36.8)$ & 0.728 \\
& 4 & $40 / 50(80)$ & $25 / 43(58.1)$ & $\mathbf{0 . 0 2 5}$ \\
& 5 & $13 / 15(86.7)$ & $15 / 21(71.4)$ & 0.424 \\
GS $>6$ & Any & $42 / 83(50.6)$ & $42 / 83(50.6)$ & 1 \\
& 3 & $2 / 18(11.1)$ & $5 / 19(26.3)$ & 0.405 \\
& 4 & $29 / 50(58)$ & $22 / 43(51.1)$ & 0.537 \\
& 5 & $11 / 15(73.3)$ & $15 / 21(71.4)$ & 0.900 \\
\hline
\end{tabular}

The original article has been corrected.

Publisher's Note Springer Nature remains neutral with regard to jurisdictional claims in published maps and institutional affiliations. 